\title{
Erratum to: Cylinders or walls? A new computational model to estimate the MR transverse relaxation rate dependence on trabecular bone architecture
}

Bernd Müller-Bierl • Olivia Louis • Yves Fierens •

Robert Luypaert $\cdot$ Johan de Mey

Published online: 1 November 2013

(C) ESMRMB 2013

Erratum to: Magn Reson Mater Phy

DOI 10.1007/s10334-013-0402-7

Nico Buls has been withdrawn from the list of authors of this article. Instead, the authors would like to acknowledge Mr. Buls for financing the language revision carried out by San Francisco Edit, San Francisco, CA.

The online version of the original article can be found under doi:10.1007/s10334-013-0402-7.

B. Müller-Bierl $(\varangle) \cdot$ O. Louis · Y. Fierens · R. Luypaert · J. de Mey

Radiologie, Universitair Ziekenhuis Brussel, Brussels, Belgium

e-mail: bernd.mueller-bierl@uzbrussel.be 